\section{TREATMENT OF MYASTHENIA GRAVIS}

BY

HENRY J. WADE, B.Sc., M.B., Ch.B.

ASSISTANT MEDICAL OFFICER, CRUMPSALl hOSPITAL, MANCHESTER ; LATE SENIOR HOUSE-PHY'SICIAN, MANCHESTER ROYAL INFIRMARY

Since the publication of M. B. Walker's original work in 1934 many workers have proved beyond dispute that physostigmine has a definite therapeutic value in the treatment of myasthenia gravis. Although its aetiology is still obscure it would appear that the defect is neither in muscle nor in nerve, but is in some way connected with the transmission of impulses across the myoneural junctions. Several observers, including Cooke and Passmore, have suggested that this defect is probably of a chemical nature. The role of creatine and creatinine in myasthenia gravis is still unknown. It has been suggested that there is a diminished metabolism of these substances, but the excretion in the case investigated was within normal limits. It is possible, therefore, that any abnormality may be one of utilization of the formed substances rather than of the formation of creatine and creatinine from their precursors.

Treatment with physostigmine hitherto has been in the direction of alleviation of symptoms. No attempt to stabilize, as it were, these unfortunate patients has been recorded. It was towards this end that the following investigations were carried out on the two cases to be described. The aim was to control the daily life of patients by a series of injections at appropriate intervals, instead of merely relieving their symptoms for a few hours. The preparations used were the standard prostigmin solution, and also the concentrated form, especially prepared for myasthenia gravis, manufactured by Messrs. Hoffmann-La Reche Ltd. Prostigmin is the dimethyl carbamic ester of 3-oxyphenyl-trimethylammonium-methyl sulphate. The observations were carried out at the Manchester Royal Infirmary.

\section{Case No. 1}

A woman of 32, a ring spinner by occupation, was admitted complaining of "talking down her nose," dysarthria, and dysphagia. The nasal speech and the difficulty in articulating her words, which symptoms she had had for some two years, were only noticeable after she had been talking for some time, and more particularly later in the day. A feature of these symptoms was that they were improved by a short period of rest. Her dysphagia was more marked towards the end of a meal, and less evident at breakfast time. Her friends had noticed a loss of expression in her face during the last two years, while she herself stated that her face is "flatter" towards the evening. She complained of no visual disturbances; there was no history of oculogyric crises, difficulty in walking, or tremor. Her previous medical history was uneventful apart from an attack of "tonsillitis " two and a half years ago, in which she complained of sore throat, and of some nasal regurgitation of fluids one week later.

\section{CLINICAL EXAMINATION}

She was fairly well built and of moderate intelligence. Her vision was good, and the optic disks were normal. There was slight bilateral ptosis, slight unsustained nystagmus to the left, and some bilateral facial weakness. The tongue was protruded in the middle line ; palatal movement was sluggish ; the uvula was elevated sluggishly in the middle line. The latter two symptoms were more marked after repetition. Nothing abnormal was discovered in the other systems.

$X$-ray of her skull proved normal. Cerebro-spinal fluid and blood Wassermann reactions were negative. Lumbar puncture showed a normal pressure, cytology, chemistry, and Lange gold curve.
The possibility of her " tonsillitis" being diphtheritic was considered, but a post-diphtheritic paresis was excluded by the length of time she had had the palsy, the fact that there had been no recovery in two and a half years, the variation of her condition during the day, and the response to treatment with prostigmin.

The diagnosis of myasthenia gravis was made, and the following treatment instituted.

\section{Summary of Treatment}

Two cubic centimetres of the standard solution of prostigmin were injected subcutaneously daily for several days. There was a considerable improvement in the speech and swallowing, and a marked alteration in her facial expression. The movements of her facial muscles, palate, and pharynx were diminished after two and a half hours, but she was able to take a meal three hours after the injections without difficulty. The dose was gradually increased to $5 \mathrm{c} . \mathrm{cm}$. a day, and the beneficial effects were noticeable for four and a half hours. The use of atropine was not necessary, as neither abdominal pain, discomfort, nor diarrhoea was produced by the injections.

The concentrated solution in a dose of $2 \mathrm{c} . \mathrm{cm}$. (equivalent to $10 \mathrm{c} . \mathrm{cm}$. of the standard solution) was given with atropine sulphate 1/100 grain. The injection produced severe abdominal pain, which was not relieved by a further dose of atropine sulphate 1/100 grain, but necessitated the exhibition of morphine sulphate $1 / 4$ grain. The effect on her myasthenic condition was not so good as with $5 \mathrm{c.cm}$. of the standard solution, and her general condition was much worse. She received further daily injections of $5 \mathrm{c.cm}$. of the standard solution without ill effects.

\section{"Stabilization"}

An attempt was now made to discover whether a series of injections throughout the day could be given so as to space out more evenly the effects of the drug. Three cubic centimetres of the standard solution were injected, without atropine, at 6.30 a.m., 11.30 a.m., and 4.30 p.m. This was repeated for several days, and it was found that, although her facial expression was fading after three hours, her palatal and pharyngeal movements were good for a further one hour.

Half a cubic centimetre of the concentrated solution, with atropine sulphate $1 / 100$ grain, was then tried at 6.30 a.m., 11.30 a.m., and 4.30 p.m. This produced an attack of abdominal pain, requiring a further injection of atropine. The effects of the drug on her facial and palatal condition were not so good as wich the standard solution - in fact she required a further 2 c.cm. of the latter in order to take a meal. This was deemed a sufficient indication for the discontinuance of the concentrated solution.

The effect of potassium chloride in a dose of 4 grams twice a day was tried, and although good results have been obtained by Laurent and Walther no effect was observed in this case, and there was no increase in the effect of prostigmin.

She was eventually " stabilized," if such a term may be used, by the injection of $4 \mathrm{c.cm}$. of the standard solution, three times a day, without atropine, and when discharged the effects of each injection were sustained for an average of four and a half hours. The symptoms returned in the following order: first the nasal intonation, then the difficulty in articulation, and lastly the difficulty in swallowing. This system of injections enabled her to take her meals without difficulty, and the results obtained were most encouraging.

\section{Case No. 2}

A girl of 19, a pupil teacher, was admitted complaining of weakness in her voice after use, dysphagia, diplopia, and a nasal tone in her speech, with difficulty in articulating her 
words. The history was that she enjoyed good health until May, 1935, when she noticed this nasal intonation on raising her voice during a practice teaching class. This at first was noticed only towards the end of the lesson, but later the onset was earlier, so much so that she had to retire from the class. She also had difficulty in articulating her words, and her friends say that her speech becomes unintelligible after she has been talking for some little time. She complained of transient diplopia for a few weeks in May, 1934, which symptom was remedied by spectacles. The diplopia recurred in May, 1935, however, and this symptom is worse in the evening than in the morning and after reading for a time. The difficulty in swallowing is noticed particularly towards the end of a meal. The characteristic feature of these symptoms is that they improve after a rest.

\section{CLINICAI EXAMINATION}

Her visual acuity was for the right eye $6 / 60$, corrected $6 / 4$; for the left eye $6 / 24$, corrected $6 / 4$; the optic disks were normal. She had slight bilateral ptosis, with an inability to close her eyes tightly; the eyelids were easily separated with only slight resistance. There was bilateral weakness of the

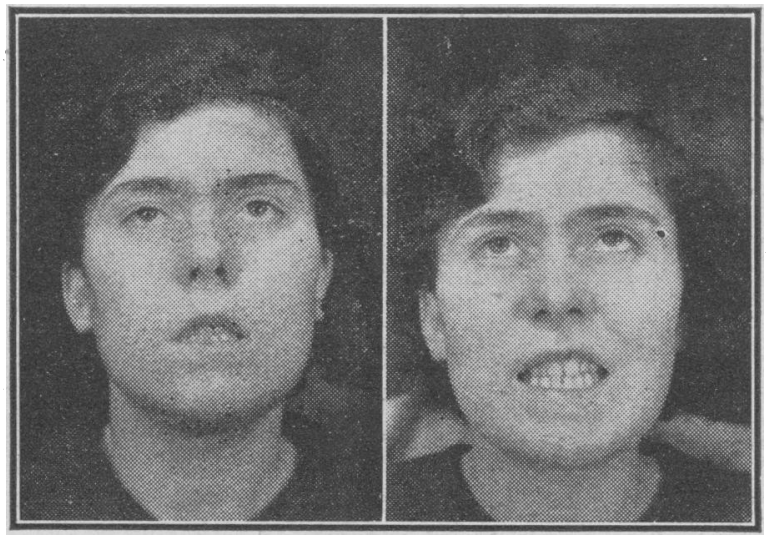

The photographs are of Case No. 2 attempting to look up and show her teeth-on the left just before an injection of prostigmin ( 6 c.con.), and on the right one and a half hours after the injection.

masseter muscle, and slight bilateral facial weakness; poor palatal movement (worse on the left), and sluggish movement of the uvula; the tongue protruded in the middle line.

Muscle power and tone in the limbs were excellent; other systems normal.

The cerebro-spinal fluid and blood Wassermann examinations were negative. Lumbar puncture showed a normal pressure, cytology, chemistry, and Lange gold curve.

\section{Summary of Treatment}

Two cubic centimetres of the standard solution of prostigmin were injected subcutaneously. She was able to read and speak intelligibly for an hour afterwards, and her difficulty in swallowing improved. The dose was increased to $5 \mathrm{c.cm}$. daily (standard solution). The response was better, and she herself described a feeling of pulling up of her eyelids and a stiffening of her face about fifteen to thirty minutes after the injection. The effect of this dose lasted about three hours. No atropine was required, there was no abdominal pain, and at the end of two hours she was able to speak distinctly, to talk, read, eat, and smile with quite a dramatic change in her facial appearance.

An equivalent dose of the concentrated solution $(1 \mathrm{c} . \mathrm{cm}$. was given with atropine sulphate $1 / 100$ grain. The patient complained twenty minutes after the injection of severe abdominal pain, which was relieved by a further injection of atropine sulphate 1/100 grain, but left her feeling very weak for the rest of the day. There was slight diarrhoea, and a much diminished effect on the facial muscles. This dose was repeated for three days, but the recurrence of the abdominal pain, despite injections of atropine, was an indication for its discontinuance.

\section{"Stabilization"}

After the encouraging results obtained with 5 c.cm. of the standard solution $I$ attempted again the continuous "stabilizing" treatment. Two cubic centimetres were given at 6.30 a.m., 11.30 a.m., and 4.30 p.m. The effects of each injection lasted about two and a half hours (average over six days). The first difficulty to return was that of swallowing, and the nasal speech was marked from two hours onwards.

The effect of potassium chloride, 4 grams twice a day and then three times a day, was tried in conjunction with prostigmin, but without any result.

Half a cubic centimetre of the concentrated solution was administered again with atropine sulphate 1/100 grain three times a day, but this solution produced such abdominal pain and discomfort that it was finally discontinued. The effect on the myasthenic condition was not so good as an equivalent dose of the standard solution, which produced no abdominal discomfort. The dose of prostigmin was increased gradually from 2 to $4 \mathrm{c.cm}$. three times a day. The average duration of the effects was found to be three and a quarter hours, and her symptoms returned in the following order: first, difficulty in swallowing, then the nasal speech and difficulty in articulation, lastly the diplopia.

Five cubic centimetres of the standard solution were given three times a day, the effect lasting on an average four hours. No atropine was given, but in this case there was slight discomfort in the abdomen thirty minutes after the injection on the second day, which was relieved by atropine sulphate $1 / 100$ grain.

Six cubic centimetres were given three times a day and the duration of the effect with this dosage was four and three-quarter hours. An occasional injection of atropine sulphate 1/100 grain was required.

The hospital routine of meal times was disturbed in order to establish exactly how she would carry on at home, and the injections were given at 7.30 a.m., 12.15 noon, and 5 p.m. It was found that with $6 \mathrm{c.cm}$. she was able to carry out her normal routine for the day, and after three days the slight abdominal pain which she experienced had diminished to such an extent that atropine was no longer necessary. She has now been instructed to give the injections to herself prior to returning home.

\section{Observations}

The results obtained in these two cases hold out considerable encouragement for the continuous method of treatment of myasthenia gravis, and many interesting facts have been disclosed.

No atropine was required in either case, using the standard solution in doses up to $5 \mathrm{c.cm}$. three times a day, yet the use of the concentrated solution in equivalent doses produced very severe abdominal pain. The motor action on the bowel of the concentrated solution would appear to be greater than its effect on the myasthenic condition, whereas the standard solution (except in doses of $6 \mathrm{c.cm}$.) had no effect on the bowel but a most marked effect on the myasthenic condition.

The fact that the second patient required no atropine after the third day with $6 \mathrm{c} . \mathrm{cm}$. of the standard solution favours the supposition of some tolerance to this drug, but this was only demonstrable in its action on the bowel, for no such tolerance has been demonstrated in over three months' observation of this patient's myasthenic condition.

Feldberg and Vartiainen demonstrated the beneficial effects of potassium ions in myasthenia gravis, but the administration of potassium chloride produced no effects in either case. 
The creatine and creatinine metabolism was not altered by the use of prostigmin: average daily excretion of creatine (Case No. 2) was 0.02 gram per day before the injections and $\mathbf{0 . 0 2 5}$ gram per day after the injections.

The creatinine excretion was 1 gram per day before the injections, and 0.9 gram per day after the injections. The diet was the same during the observations, and these findings agree with those of Cooke and Passmore.

The injections produced no systemic disturbance and caused no inconvenience to the patients, and the psychological improvement in their outlook was very gratifying. The two cases are being kept under observation, and it is hoped that favourable reports of their progress will be given at some future date.

These observations have been made while holding the appointment of house-physician to Professor A. Ramsbottom in the Royal Infirmary, Manchester. I am indebted to Professor Ramsbottom and Mr. Geoffrey Jefferson for access to their cases and for helpful advice and criticisms ; to Dr. G. E. Loveday and the clinical laboratory for the laboratory investigations; and to Dr. Paterson of the $x$-ray department for his co-operation in regard to the photography.

\section{BibliogRAPHY}

Aeschlimann, J. A., and Reinert, M.: Journ. Pharmacol. and Exper. Therap., 1931, xliii, 413.

Boothby, W. M.: Arch. Int. Med., 1934, liii, 39.

Brown, D. Denny: Lancet, 1935, i, 767.

Carmichael, E. A., Fraser, F. R., McKelvey, D., and Wilkie, D. P. D.: Lancet, 1934, i, 942.

Cooke, A. M., and Passmore, R.: Quart. Journ. Med., 1936, v, 21.

Cope, O., Corkhill, A. B., Marks, H. P., and Ochoa, S.: Journ. of Physiol. 1934, ixxxii, 305 .

Cuthbertson and Machlachlan, T. K.: Quart. Journ. Med., 1934, N.S., iii, 411.

Dale, H. H.: Lancet, 1934, i, 305.

Feldberg, W., and Vartiainen, A.: Journ. of Physiol., 1934, lxxxiii, 103.

Hunter: Creatine and Creatinine, London, 1928

İmrie, G. C., and Jenkinson, C. M.: Journ. of Physiol., 1933, lxxix 218.

Laurent, L. P. E.: British Medical Journal, 1935, i, 463 ; Lancet, $1935, i, 841$.

Laurent, L. P. E., and Walther, W. W.: Lancet, 1935, i, 1434.

McAlpine, D.: Ibid., 1934, $i, 180$

Pritchard, E. A. B.: Journ. of Physiol., 1933, lxxviii, 3 ; Lancet, $1935, i, 432$.

Pritchard, E. A. B., and Walker, M. B.: Journ. of Physiol., 1935, lxxxiv, 35

Walker, M. B.: Lancet, 1934, i, 1200 ; Proc. Roy. Soc. Med., 1935, xxviii, 759 ; Lancet, 1935, ii, 47.

A. A. Levi and C. M. Krinsky (New England Journ. Med., February 20th, 1936, p. 362) record an investigation of the effect of administering coramine to post-partum patients under the analgesic influence of some barbituric acid drugs. The series studied consisted of forty consecutively admitted patients who had received nembutal and paraldehyde. To twenty of these patients $5 \mathrm{c.cm}$. was given intramuscularly after the third stage of delivery had been completed; the average patient had in the meantime come round from the mild degree of ether anaesthesia which had been induced. The remaining twenty served as controls, and significant differences were observed between the two groups. Recovery of consciousness supervened in an average of seven hours and fortyeight minutes in those not so treated, while the time was five hours and forty-five minutes for the coramine group. The average doses of paraldehyde were almost identically the same in all patients-namely, 4.4 grains of nembutal and 5.1 drachms of paraldehyde for the control group, and 4.7 grains and $\mathbf{4 . 5}$ drachms respectively for the coramine group. It was also noticed that there were fewer catheterizations necessary in this latter group. One patient, not in this series, who seemed to be dying after exceptionally heavy doses of nembutal and paraldehyde, was restored to consciousness three-quarters of an hour after the administration of coramine, and the pronounced cardiac and respiratory embarrassment passed off. The authors add that coramine is undoubtedly of value when the respiration is so depressed that the patient cannot inspire carbon dioxide and oxygen mixtures.

\section{TREATMENT OF THE AMBLYOPIC EYE \\ BY}

W. HEDLEY SUMMERSKILL, M.B., B.S., D.O. Clinical ASSISTANT, ROYAL EYE HOSPITAL

Von Graefe once described amblyopia as a condition " where the doctor and patient see nothing" ; to-day we might quite well add the reproach " and do nothing." Treatment of the virtual blindness of these eyes is almost entirely neglected after early childhood, despite the disability that it undoubtedly involves. This is the outcome of an assumption that the loss of visual acuity is either incurable, or that improvement in function such as can be obtained by treatment is not commensurate with the effort involved.

The object of this paper is to show, first, that this assumption rests on very flimsy pathological evidence, unsupported by the clinical results that can be obtained by treating amblyopia ; and, secondly, that these eyes, even when the blindness is unilateral, represent in this mechanical age a grave economic and social disability more than justifying the effort of securing useful function. To assess the value of treatment $I$ have recently treated a group of amblyopic eyes selected at random from hospital and private practice. They exhibited three clinical types of reduced visual àcuity:

1. Amblyopia ex anopsia-the legacy of childhood strabismus (Cases 1 to 5 ).

2. Congenital amblyopia presumed to result from the presence of some developmental defect (Cases 6 and 7).

3. Amblyopia of the type associated with corneal nebulae, ametropia, or other objective evidence of interference with infantile education in macular perception. The blindness of many eyes damaged in early childhood by disease or trauma is frequently in a greater degree due to an associated amblyopia than to the optical effect of the sequels of the lesion, and their treatment may result in a dramatic increase of visual acuity, despite comparatively gross ophthalmoscopic signs (Case 8).

In my opinion these three forms have a common pathological basis, consisting of an obstruction in the psychological phase of the visual arc. This interference with conscious perception may be a purposive act to avoid the psychic trauma involved by some fusion dysfunction or the passive result of the incomplete conditioning of the pathways which subserve syncritic vision. Anatomical defects in the visual arc play, I believe, a comparatively small part in the pathology of amblyopia.

Toxic and similar forms of amblyopia are not considered, as their connexion with these groups is only an accident of nomenclature.

\section{The Value of Treatment}

There are certain unproven assumptions regarding the pathology of the amblyopic eye which have tended to discourage efforts at treatment. It has been assumed that a progressive and irreversible deterioration from disuse takes place somewhere in the visual arc of the " lazy" eye. Certainly, as the suppression becomes more habitual the residual function tends to get less until only perception of light with no power of central fixation may remain. This does not necessarily mean, however, that any concurrent organic change in the eye or central pathways has taken place. In fact, careful histological examination has failed to demonstrate any secondary change.

There is, therefore, no a priori justification for presuming that, if the suppression habit is overcome, a return of visual function might not be expected. The results 